\title{
UJI EFEKTIVITAS REPELLENT SEDIAAN LOTION KOMBINASI MINYAK ATSIRI DAUN ZODIA (Evodia suaveolens Scheff) DAN MINYAK ATSIRI BATANG SERAI (Cymbopogon citratus) TERHADAP NYAMUK Aedes aegypti L.
}

\section{TEST OF REPELLENT EFFECTIVENESS OF LOTION CONTAINING THE COMBINATION OF ESSENTIAL OILS OF ZODIA LEAF OIL (Evodia suaveolens Scheff) AND LEMONGRASS (Cymbopogon citratus) ON Aedes aegypti L.}

\author{
Puput Mirawati, Eva Susanty Simaremare, Rani Dewi Pratiwi \\ Program Studi Farmasi, Fakultas MIPA, Universitas Cenderawasih, Jayapura \\ Kampus Uncen Waena, JI. Perumnas III Waena-Jayapura Papua 99358 \\ Email: eva_smare@yahoo.com (Eva Susanty Simaremare)
}

\begin{abstract}
ABSTRAK
Tanaman zodia (Evodia suaveolens Scheff) dan serai (Cymbopogon citratus) merupakan tanaman asli Indonesia yang dapat mengusir nyamuk dan serangga yang berada di sekitarnya. Tujuan penelitian ini adalah membuat dan mengevaluasi lotion zodia-serai yang dapat mengusir nyamuk Aedes aegypti serta menentukan daya proteksi tiga formula lotion. Metode yang digunakan adalah distilasi uap minyak atsiri dari daun zodia dan batang sereh, formulasi serta evaluasi lotion, uji daya proteksi, dan analisis data. Hasil dari penelitian ini adalah lotion memiliki $\mathrm{pH} 5$, pemeriksaan uji sentrifugasi menunjukkan lotion tidak terpisah/stabil. Efektivitas penghalau nyamuk sediaan lotion paling tinggi pada jam 0 dengan daya halau 100\%. Kombinasi terbaik sediaan lotion kombinasi minyak atsiri daun zodia dan minyak atsiri batang serai sebagai repellent nyamuk Aedes aegypti yaitu 7:3.
\end{abstract}

Kata kunci: zodia (Evodia suaveolens Scheff), serai (Cymbopogon citratus), lotion, repellent, Aedes aegypti.

\begin{abstract}
Zodia (Evodia suaveolens Scheff) and lemongrass (Cymbopogon citratus) are native Indonesian plants with repellant activity against mosquitoes and insects. The purpose of this research were to formulate and evaluate the repellant activity of zodia-serai lotion against Aedes aegypti and determine the protection power of three formulas of lotion. The method used in this research including steam distillation of essential oil from zodia leaves and lemongrass, formulation and evaluation of lotions, power protection test, and data analysis. The result of this research showed that lotion had acidic $\mathrm{pH}$ of 5, and they were stable without separation after stability evaluation with centrifugation. The most effective repellant activity of the lotion was exhibited at 0 hours with $100 \%$ of repellency. The best combination of essential oils of zodia (Evodia suaveolens Scheff) and lemongrass (Cymbopogon citratus) as Aedes aegypti repellent was at ratio of 7:3.
\end{abstract}


PHARMACY: Jurnal Farmasi Indonesia

p-ISSN 1693-3591

(Pharmaceutical Journal of Indonesia)

e-ISSN 2579-910X

Vol.15 No. 01 Juli 2018

Key words: zodia (Evodia suaveolens Scheff), lemongrass (Cymbopogon citratus), lotion, repellent, Aedes aegypti. 


\section{Pendahuluan}

Indonesia merupakan wilayah endemis beragam penyakit tropis seperti penyakit yang ditularkan oleh Aedes aegypti yaitu penyakit Demam Berdarah Dengue (DBD). Penyakit DBD merupakan penyakit tropis yang paling banyak dilaporkan. Lebih dari 100 negara dan 2,5 miliar penduduk dunia bermukim di daerah endemik dengue (Juniarti, 2011). Saat ini penyakit demam berdarah termasuk penyakit yang sangat meresahkan masyarakat karena penyebarannya sangat cepat dan dapat menyebabkan kematian (Kardinan, 2007).

Kenyataan tersebut menuntut perlunya memberantas nyamuk Aedes aegypti dengan berbagai cara salah satunya dengan menggunakan bahan alami. Bahan alami ini biasanya berbahan dasar tanaman (Novizan, 2002) yang bekerja dengan cara mengusir nyamuk dalam bentuk lotion, krim, atau pakaian yang dapat melindungi tubuh dari gigitan nyamuk.

Tanaman zodia (Evodia suaveolens Scheff) merupakan tanaman asli Indonesia yang habitat utamanya berasal dari Irian (Papua) (Kardinan, 2003; Kardinan 2004; Kardinan 2005). Tanaman zodia dipercaya mampu mengusir nyamuk dan serangga yang berada di sekitar tanaman (Kardinan dan Jasni, 2001; Kardinan dan Dhalimi, 2010). Tanaman zodia yang termasuk ke dalam famili Rutaceae, mengandung evodiamin dan rutaekarpin. Senyawa linalool yang terdapat pada tanaman zodia sudah sangat dikenal sebagai pengusir repellent nyamuk. Masyarakat Papua biasanya menggosok kulit mereka dengan menggunakan daun pada tanaman zodia sebelum masuk ke hutan agar terlindungi dari serangan serangga khususnya nyamuk (Simaremare dkk., 2017).

Tanaman serai (Cymbopogon citratus) adalah salah satu tanaman penghasil minyak atsiri yang didominasi sitral (Guenter, 1948) yang merupakan bahan baku dalam pembuatan sabun, shampo, pasta gigi, lotion, gel antinyamuk, pestisida nabati, disinfektan dan bahan pengkilap (Kardinan, 2003). Konsentrasi minyak serai yang umum digunakan dalam produk penolak serangga berkisar antara $0,05 \%$ hingga $15 \%$ baik secara tunggal maupun dikombinasikan dengan berbagai jenis minyak atsiri (Bernard, 2000).

Menurut hasil penelitian yang dilakukan oleh Kardinan (2004) di Balai 
Penelitian Tanaman Rempah dan Obat (Balittro) dengan gas kromatografi, minyak yang disuling dari daun tanaman zodia mengandung linalool (46\%) dan $\alpha$ pinene $(13,26 \%)$, sehingga tanaman zodia mampu menghalau nyamuk selama 6 jam dengan daya halau (daya proteksi). Menurut Purnamasari dkk. (2015), semakin besar konsentrasi minyak zodia maka daya proteksinya semakin besar yakni untuk formula lotion dengan konsentrasi 1,5\% minyak zodia memiliki daya proteksi $88,07 \%$ pada jam ke-0; 83,35\% untuk daya proteksi lotion dengan minyak zodia $1 \%$; serta $66,64 \%$ untuk lotion dengan 0,5\%.

Oleh karena lotion minyak atsiri zodia yang sudah pernah dikerjakan masih sangat berbau khas maka akan dilakukan penelitian untuk melihat apakah kombinasi minyak atsiri daun zodia dan batang serai dapat digunakan sebagai repellent nyamuk Aedes aegypti L. yang efektif dengan menggunakan formulasi yang dikembangkan sebagai lotion serta mampu mengurangi bau khas yang terdapat pada daun zodia.

\section{Metode Penelitian}

Penelitian dilakukan Di Laboratorium Farmasi, Jurusan Biologi, dan Laboratorium Pendidikan Kimia, dan Laboratorium Teknologi Farmasi, Universitas Cenderawasih, Jayapura. Alat dan Bahan

Alat-alat yang digunakan dalam penelitian yaitu: seperangkat alat distilasi uap, stamper, mortar, timbangan analitik, alat gelas laboratorium, penangas air, kertas $\mathrm{pH}$, alat gelas, sentrifugasi, rotary evaporator, termometer, hot plate, botol vial, lemari pendingin, oven, kandang nyamuk, mikroskop, blender, ayakan no. 60 mesh, pembakar Bunsen, pinset, dan alat sedot nyamuk. Bahanbahan yang digunakan pada penelitian ini yaitu minyak atsiri daun zodia (Evodia cuaveolens Scheff), minyak atsiri serai dapur (Cymbopogon citrarus), parrafin cair, asam stearat, lanolin, setil alkohol, propilen glikol, natrium lauril sulfat, metil paraben, propil paraben, parfum, aluminium foil, kertas saring dan akuades, ammonia 25\%, kloroform, pereaksi Dragendorff, pereaksi mayer, asam klorida, pereaksi Liebermann-burchard, anhidrat asetat, asam sulfat pekat, serbuk magnesium, asam klorida, etanol 1:1, amil alkohol, etanol $70 \%$, larutan $\mathrm{FeCl}_{3} 5 \%$.

Jalannya Penelitian

1. Pengumpulan dan penyediaan bahan penelitian 
Sampel daun zodia dan batang serai dapur diperoleh dari kebun Desa Kertosari, Distrik Sentani Barat, Jayapura, Papua, dan batang serai (Cymbopogon citrarus) diperoleh dari Koya Barat. Nyamuk yang digunakan sebagai hewan uji yaitu nyamuk yang ada di lingkungan kampus FMIPA-Uncen.

2. Pembuatan minyak atsiri daun zodia dan batang serai

Masing-masing minyak daun zodia dan batang serai dibuat dengan cara didistilasi uap. Masingmasing daun zodia dan batang serai dimasukkan ke dalam panci distilasi sebanyak $1 \mathrm{~kg}$ kemudian diuapkan selama 8 jam. Minyak atsiri yang dihasilkan dibebaskan dari sisa air dengan menggunakan $\mathrm{Na}_{2} \mathrm{SO}_{4}$ anhidrat dan disimpan dalam botol vial tertutup dalam lemari pendingin.

3. Analisis minyak atsiri zodia dan serai dengan KLT

Plat KLT yang mengandung silika gel $\mathrm{GF}_{254}$ dengan ukuran $3 \times 5$ cm disiapkan, kemudian sampel minyak zodia dan sampel minyak batang serai ditotolkan dari ujung plat dengan menggunakan pipet kapiler. Plat KLT dibiarkan sesaat kemudian plat KLT dimasukkan ke dalam bejana KLT yang sudah jenuh dengan uap pelarut. Pelarut yang digunakan adalah toluena: etil asetat (97:3, v/v). Plat KLT kemudian dideteksi dengan menggunakan $\mathrm{H}_{2} \mathrm{SO}_{4} \quad 10 \%$ dalam etanol. Plat KLT selanjutnya diamati noda-noda yang timbul setelah dipanaskan selama 3 menit. Harga Rf yang telah dihitung dan warna noda kemudian dibandingkan dengan data sekunder dari literatur (Astuti, 2006).

4. Formulasi lotion zodia-serai

$$
\text { Na-lauril sulfat dilarutkan }
$$
dengan sejumlah air di atas penangas air kemudian secara bertahap metil paraben dan propil paraben dilarutkan ke dalam larutan Na-lauril sulfat, kemudian ditambahkan akuades dan suhu dijaga agar tetap 70-75 ㅇ. S. Secara terpisah fase minyak dilarutkan di atas penangas air secara bertahap mulai dari asam stearat, setil alkohol, lanolin, kemudian tambahkan parafin cair, suhu dijaga agar tetap 70-75 ㅇ․ Minyak atsiri daun zodia dan batang serai dimasukkan di atas sediaan yang telah menjadi lotion. Mortir dipanaskan dengan air panas dan ditutup dengan aluminium foil. Minyak atsiri tanaman zodia dan 
batang serai dan fase air sedikit demi sedikit dicampurkan dengan fase minyak dalam mortir yang telah dipanaskan, sampai membentuk masa lotion yang stabil dan homogen hingga suhu mencapai 40-45 으 kemudian sediaan lotion disimpan dalam wadah tertutup.

Tabel 1. Formulasi lotion zodia-serai

\begin{tabular}{lccc}
\hline \multirow{2}{*}{ Bahan } & \multicolumn{3}{c}{ Formula } \\
\cline { 2 - 4 } & F I & F II & F III \\
\hline Minyak atsiri daun zodia & 0,7 & 0,5 & 0,3 \\
Minyak atsiri batang serai & 0,3 & 0,5 & 0,7 \\
Paraffin cair (v/v) & $3 \mathrm{~mL}$ & $3 \mathrm{~mL}$ & $3 \mathrm{~mL}$ \\
Asam stearat & $2 \mathrm{~g}$ & $2 \mathrm{~g}$ & $2 \mathrm{~g}$ \\
Lanolin & $2 \mathrm{~g}$ & $2 \mathrm{~g}$ & $2 \mathrm{~g}$ \\
Na lauril sulfat & $2 \mathrm{~g}$ & $2 \mathrm{~g}$ & $2 \mathrm{~g}$ \\
Metil paraben (b/v) & $0,12 \mathrm{~g}$ & $0,12 \mathrm{~g}$ & $0,12 \mathrm{~g}$ \\
Propil paraben (b/v) & $0,10 \mathrm{~g}$ & $0,10 \mathrm{~g}$ & $0,10 \mathrm{~g}$ \\
Setil alkohol & $2 \mathrm{~g}$ & $2 \mathrm{~g}$ & $2 \mathrm{~g}$ \\
Akuades add & $100 \mathrm{~mL}$ & $100 \mathrm{~mL}$ & $100 \mathrm{~mL}$ \\
\hline
\end{tabular}

5. Pengumpulan nyamuk Aedes aegypti $\mathrm{L}$.

Proses pengumpulan nyamuk dilakukan pada pukul 08.00-10.00 WIT dan 14.00-16.00 WIT dengan menyediakan beberapa sukarelawan dan menggunakan baju berwarna hitam di dalam hutan kampus. Nyamuk akan mendekati sukarelawan kemudian alat sedot yang telah disiapkan, dipakai untuk menangkap nyamuk.

6. Evaluasi mutu fisik sediaan lotion

Evaluasi dilakukan setelah sediaan lotion kombinasi minyak atsiri daun zodia dan minyak atsiri batang serai terbentuk, setelah 1 hari penyimpanan.

a. Organoleptis

Uji organoleptis dilakukan secara visual terhadap sediaan lotion kombinasi minyak atsiri daun zodia dan minyak atsiri batang serai untuk mengetahui warna sediaan, konsistensi sediaan dan bau dari sediaan lotion.

b. Homogenitas

Uji homogenitas sediaan lotion dilakukan dengan cara mengamati hasil pengolesan lotion pada plat kaca. Sebanyak 0,5 lotion kombinasi minyak 
atsiri daun zodia dan minyak atsiri batang serai dioleskan di atas kaca objek, kemudian dikatupkan dengan kaca objek lain, lalu diamati kehomogenan lotion tersebut (Yuniarsih, 2010).

c. $\mathrm{pH}$

Sebanyak 0,5 gram lotion kombinasi minyak atsiri daun zodia dan batang serai diencerkan dengan $5 \mathrm{~mL}$ akuades. Penentuan sifat sediaan asam/basa sediaan lotion kombinasi minyak atsiri daun zodia dan minyak atsiri batang serai dapat mengunakan kertas pH (Yuniarsih, 2010).

d. Sentrifugasi

Sebanyak 2 gram lotion kombinasi minyak atsiri daun zodia dan minyak atsiri batang serai dimasukkan ke dalam tabung sentrifugasi kemudian diputar pada 3000 rpm selama 30 menit, kemudian diamati apakah terjadi pemisahan.

e. Patch test

Uji keamanan lotion kombinasi minyak atsiri daun zodia dan minyak batang serai dilakukan terhadap 10 relawan yang dioleskan variasi lotion kombinasi minyak atsiri daun zodia dan minyak atsiri batang serai dapur selama 15 menit kemudian dilihat reaksinya, terjadi iritasi/alergi atau tidak (Yuniarsih, 2010).

f. Uji daya sebar

Sebanyak 0,5 gram lotion kombinasi minyak atsiri daun zodia dan minyak atsiri batang serai diletakkan di atas kaca arloji kemudian di atas lotion diletakkan kaca arloji lainnya dan dibiarkan selama 1 menit. Lotion di dalam kaca arloji tersebut, kemudian ditambahkan beban 50, 100, dan $150 \mathrm{~g}$, didiamkam selama 1 menit lalu dicatat diameter penyebarannya (Agustina, 2010).

g. Uji daya lekat

Sebanyak 0,25 gram lotion kombinasi minyak atsiri daun zodia dan minyak atsiri batang serai diletakkan di atas gelas objek dan ditekan dengan beban $1 \mathrm{~kg}$ selama 5 menit. Selanjutnya beban sebanyak 80 gram dilepaskan, dicatat waktu disaat kedua gelas objek terlepas (Agustina, 2010). 
7. Uji efektifitas sebagai repellent

Pengujian dilakukan ke dalam kurungan nyamuk berukuran $30 \times 30$ $\mathrm{cm}$ yang dindingnya terbuat dari kain kasa nilon. Kurungan yang disediakan sebanyak III buah ditujukan untuk pengujian sampel, kontrol (-), dan kontrol (+). Masingmasing dimasukkan 30 ekor nyamuk Aedes aegypti yang sama sekali belum menghisap darah. Kemudian lengan dioleskan 300 mg lotion minyak atsiri daun zodia dan minyak atsiri batang serai dari setiap formula uji. Lalu lengan yang telah terolesi lotion dimasukkan dalam kurungan nyamuk selama 15 menit setiap 15 menit. Hal ini juga dilakukan untuk kontrol (+) dan (-). Efektivitas terhadap gangguan nyamuk dapat ditentukan dengan rumus:

$$
\mathrm{Dp}=\frac{K-P}{K} \times 100 \%
$$

Dimana:

Dp: Daya proteksi.

$\mathrm{K}$ : Angka hinggap pada lengan kontrol (lotion tidak mengandung minyak atsiri daun zodia dan minyak atsiri batang serai).

$P$ : Angka hinggap pada lengan terolesi lotion minyak atsiri daun zodia dan minyak atsiri batang serai.

\section{Hasil dan Pembahasan}

Hasil Distilasi Uap Sampel Zodia dan Serai

Proses penyarian minyak atsiri daun zodia dan batang serai dilakukan dengan menggunakan metode distilasi uap (DU) karena minyak atsiri memiliki sifat yang mudah menguap sehingga saat terkena uap panas air minyak atsiri daun zodia dan minyak atsiri pada batang zodia dan serai akan ikut terbawa keluar dan akan menghasilkan destilat (Lestari dan Simaremare, 2017). Proses distilasi menghasilkan minyak atsiri daun zodia sebanyak 7,29 mL dari \pm 2700 gram sampel daun zodia dan 7,54 $\mathrm{mL}$ dari \pm 3200 gram sampel batang serai yang telah kering. Hasil pemeriksaan minyak ditunjukkan pada Tabel 2.

\section{Formulasi Lotion Minyak Atsiri Daun} Zodia dan Batang Serai

Formulasi menjadi bentuk sedian farmasi sudah pernah dikerjakan baik sebagai mat elektrik (Lestari dan Simaremare, 2017), sabun (Simaremare dkk., 2017; Simaremare dkk., 2018), dan lotion (Purnamasari dkk., 2015; Simaremare dan Gunawan. 2015). Pembuatan tiga formula lotion 
kombinasi minyak atsiri daun zodia dan

minyak atsiri batang serai dengan ini

menggunakan kombinasi zodia dan

serai dengan variasi konsentrasi (zodia:serai) yaitu Formula I (7:3);

Formula II (1:1); dan Formula III (3:7). Ketiga formulasi menghasilkan lotion yang baik.

Tabel 2. Hasil uji organoleptik lotion kombinasi minyak atsiri daun zodia (Evodia suaveolens Scheff) dan batang serai (Cymbopogon citratus)

\begin{tabular}{lll}
\hline \multicolumn{1}{c}{ Pemeriksaan } & \multicolumn{1}{c}{ Hasil Pemeriksaan } \\
\hline & Minyak Atsiri Daun Zodia & \\
a. & Organoleptik & - Cair seperti minyak \\
& - Wujud & - Kuning bening \\
& - Warna & - Khas menyengat \\
- Bau & 6 \\
b. Keasaman $(\mathrm{pH})$ & $76^{\circ} \mathrm{C}$ \\
\hline
\end{tabular}

Minyak Atsiri Batang Serai

a. Organoleptik minyak atsiri batang serai

- Wujud

- Warna

- Bau

b. Keasaman $(\mathrm{pH})$
- Cair seperti minyak

- Kuning bening

- Khas menyengat
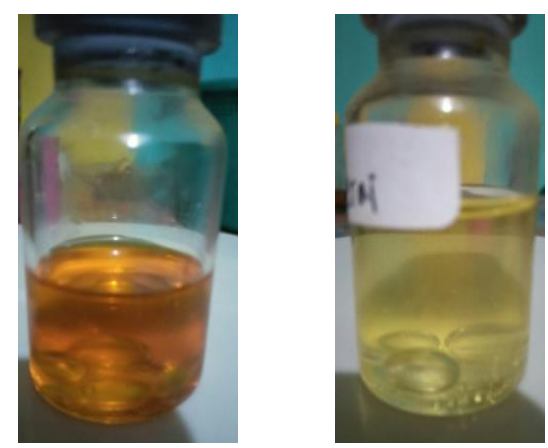

Gambar 1. Hasil distilat minyak atsiri daun zodia (kiri) dan minyak atsiri batang serai (kanan) 


\section{Evaluasi Sediaan Lotion}

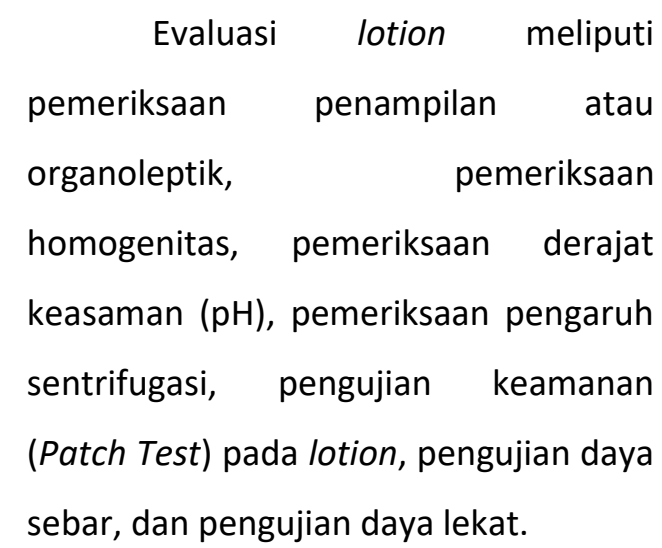

1. Uji organoleptik

Pada pemeriksaan organoleptik, formula basis menghasilkan lotion berwarna putih susu dan tidak berbau minyak atsiri sedangkan formula I, II, dan III berwarna putih kekuningan dan berbau khas minyak atsiri. Hal ini disebabkan karena ketiga formula mengandung senyawa minyak atsiri yang berasal dari kombinasi minyak atsiri zodia dan minyak atsiri batang serai.

2. Uji homogenitas

Pada uji homogenitas terhadap ketiga lotion formula uji, menunjukkan bahwa lotion memiliki homogenitas yang baik. Hal ini ditujukkan dengan adanya warna sediaan yang merata serta memiliki massa lotion yang terbentuk. Sediaan lotion yang homogen mengindikasikan bahwa ketercampuran dari bahan-bahan lotion dengan minyak atsiri daun zodia dan batang serai bagus karena tidak terdapat gumpalan pada sediaan ketiga formula uji. Aroma dan warna pada lotion yang merata menunjukan bahwa hasil evaluasi formula lotion minyak atsiri zodia dan batang serai sudah baik dan memenuhi syarat mutu fisik.

3. Uji pH

Nilai $\mathrm{pH}$ untuk keempat sedian lotion uji sebesar 5 dan berada dalam kisaran pH kulit manusia 5,5-6,5. Pengukuran derajat keasaman lotion kombinasi minyak atsiri daun zodia dan batang serai perlu dilakukan karena sediaan lotion repellent ditujukan untuk pemakaian topikal yang berguna untuk menghindari terjadinya iritasi pada kulit. Lotion ini aman digunakan karena tidak terlalu asam dan tidak terlalu basa.

4. Uji sentrifugasi

Uji sentrifugasi bertujuan untuk melihat kestabilan Iotion. Dari hasil pemeriksaan uji sentrifugasi maka didapatkan hasil bahwa formula uji lotion minyak atsiri daun zodia dan minyak atsiri batang serai menunjukkan tingkat kestabilan yang baik sehingga memenuhi salah satu syarat sediaan lotion. 
5. Uji patch test

Pada pengujian keamanan sediaan lotion dengan melakukan uji patch terhadap 30 panelis yang telah diolesi lotion kombinasi minyak atsiri daun zodia dan minyak atsiri batang serai pada punggung tangan dan di udara terbuka selama 15 menit terhadap panelis, 4 orang mengalami alergi berupa rasa panas dan gatal pada tangan yang telah diolesi sediaan lotion. Sehingga dari hasil uji Patch Test menunjukkan bahwa formula lotion tersebut masih aman digunakan sebagai sediaan topikal karena pada 26 relawan tidak menunjukkan adanya tanda-tanda alergi.

6. Uji daya sebar

Pengujian daya sebar lotion kombinasi minyak atsiri daun zodia dan minyak atsiri batang serai dilakukan untuk melihat kemampuan sediaan lotion dapat menyebar secara merata pada kulit. Pengukuran daya sebar dapat dilakukan dengan menggunakan kaca arloji, yang diolesi lotion kemudian diberi tanda menggunakan penggaris. Nilai diameter rata-rata diperoleh dari menghitung hasil penyebaran lotion yang menunjukkan daya sebar lotion yang diaplikasikan pada kulit.

Hasil uji daya sebar lotion menunjukkan adanya perbedaan yang signifikan pada masing-masing formula lotion (Tabel 3). Formula I berbeda signifikan dengan formula II, formula III, dan basis, sedangkan formula II juga berbeda signifikan dengan formula III. Perbedaan daya sebar yang signifikan pada masingmasing formula lotion dapat disebabkan karena adanya peningkatan konsentrasi lotion sehingga konsistensi sediaan semakin encer dan daya sebar lotion semakin luas.

7. Uji daya lekat

Pengamatan uji daya lekat dilakukan untuk mengetahui seberapa jauh lotion dapat menempel di kulit sehingga mendapatkan efek terapi yang diinginkan. Daya lekat lotion yang terlalu kuat menyebabkan pernafasan dalam kulit terhambat, begitu sebaliknya jika terlalu lemah efek terapinya tidak maksimal. 
Tabel 3. Uji daya sebar lotion kombinasi minyak atsiri daun zodia (Evodia suaveolens Scheff) dan batang serai (Cymbopogon citratus)

\begin{tabular}{ccc}
\hline Formulasi & Uji Daya Sebar Awal & Uji Daya Sebar Akhir \\
\hline I & 4,3 & 5,7 \\
II & 3,4 & 5,2 \\
III & 3,3 & 4,3 \\
IV & 3,1 & 3,4 \\
\hline
\end{tabular}

Tabel 4. Uji daya lekat lotion kombinasi minyak atsiri daun zodia (Evodia suaveolens Scheff) dan batang serai (Cymbopogon citratus)

\begin{tabular}{ccc}
\hline Formulasi & Uji Daya Sebar Awal & Uji Daya Sebar Akhir \\
\hline I & 5 detik & 15 detik \\
II & 6 detik & 12 detik \\
III & 5 detik & 7 detik \\
IV & 7 detik & 10 detik \\
\hline
\end{tabular}

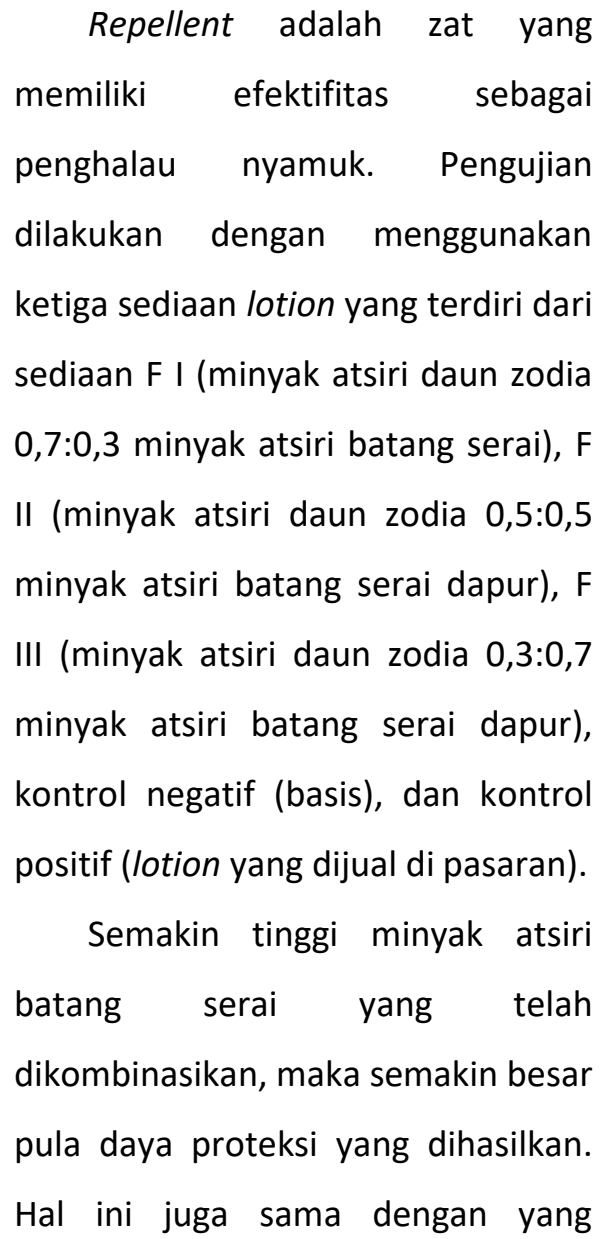

Repellent adalah zat yang memiliki efektifitas sebagai dilakukan dengan menggunakan ketiga sediaan lotion yang terdiri dari sediaan F I (minyak atsiri daun zodia 0,7:0,3 minyak atsiri batang serai), $F$ II (minyak atsiri daun zodia 0,5:0,5 minyak atsiri batang serai dapur), $F$ III (minyak atsiri daun zodia 0,3:0,7 minyak atsiri batang serai dapur), positif (lotion yang dijual di pasaran). Hal ini juga sama dengan yang dilakukan Simaremare pada sediaan sabun (Simaremare dkk., 2017; Simaremare dkk., 2018). Dapat dilihat pada Tabel 5 bahwa F III yaitu dengan perbandingan minyak atsiri daun zodia 0,3:0,7 minyak atsiri batang serai menghasilkan daya proteksi dari jam ke-0 sebesar $100 \%$ hingga jam ke-6 sebesar 81,4\% dibandingkan dengan $F \quad I$ yaitu dengan perbandingan minyak atsiri daun zodia 0,7:0,3 minyak atsiri batang serai menghasilkan daya proteksi dari jam ke-0 sebesar 100\% sampai jam ke-6 sebesar 59,2\% daya proteksi, F II dengan kombinasi minyak atsiri daun zodia sebesar 0,5:0,5 minyak atsiri batang serai 
dari menit ke-0 menghasilkan daya proteksi sebesar $100 \%$ hingga menit ke-6 sebesar $66,6 \%$ daya proteksi. Sedangkan pada kontrol negatif pada jam ke-0 memiliki daya proteksi $90 \%$ hingga jam ke-6 memiliki daya proteksi sebesar 29,6\%, namun pada kontrol positif yaitu pengujian menggunakan sampel lotion anti nyamuk menunjukan daya proteksi dari jam ke-0 yaitu 100\% hingga jam ke-6 yaitu sebesar 25,9\%.

Tabel 5. Persentase daya halau pada lotion kombinasi minyak atsiri daun zodia (Evodia suaveolens Scheff) dan batang serai (Cymbopogon citratus)

\begin{tabular}{cccccccc}
\hline \multirow{2}{*}{ Formula } & \multicolumn{7}{c}{ Efektivitas Daya Halau (\%) } \\
\cline { 2 - 8 } & 0 & 1 & 2 & 3 & 4 & 5 & 6 \\
\hline F I & 100 & 92,3 & 80 & 83,3 & 72,2 & 72 & 59,2 \\
F II & 100 & 100 & 86,6 & 83,3 & 81,1 & 72 & 66,6 \\
F III & 100 & 100 & 93,3 & 94,4 & 90,9 & 88 & 81,4 \\
KN & 90 & 92,3 & 80 & 72,2 & 54,5 & 32 & 29,6 \\
KP & 100 & 53,8 & 80 & 72,2 & 45,4 & 28 & 25,9 \\
\hline
\end{tabular}

Keterangan:

FI : Formula I (minyak atsiri daun zodia 0,7:0,3 minyak atsiri batang serai)

F II : Formula II (minyak atsiri daun zodia 0,5:0,5 minyak atsiri batang serai)

F III : Formula III (minyak atsiri daun zodia 0,3:0,7 minyak atsiri batang serai)

KN : Kontrol negatif (basis sediaan lotion tanpa minyak atsiri)

KP : Kontrol positif (lotion yang berada di pasaran)

Perubahan potensi lotion kombinasi minyak atsiri daun zodia dan minyak atsiri batang serai dari jam ke 06 dipengaruhi oleh dua hal. Pertama adalah penguapan senyawa-senyawa kimia yang terdapat dalam lotion kombinasi minyak atsiri daun zodia dan minyak atsiri batang serai yang semakin meningkat seiring berjalannya waktu, sehingga bau dari lotion akan hilang dan mengakibatkan penurunan potensi repellent. Yang kedua adalah aktivitas nyamuk Aedes aegypti yang semakin menurun seiring bertambahnya waktu, sehingga seakan-akan nyamuk yang hinggap pada lengan semakin sedikit seperti yang disampaikan oleh Purnamasari dkk. (2015) dengan bertambahnya waktu, daya proteksi terhadap nyamuk atau efektivitas repellent semakin menurun. Penurunan aktivitas nyamuk tersebut disebabkan oleh perbedaan umur dan keadaan oviparitas dari masing-masing nyamuk. Lamanya waktu proteksi terhadap hinggapan dan gigitan nyamuk pada 
masing-masing konsentrasi dipengaruhi oleh jumlah kandungan senyawa yang berfungsi sebagai repellent yang terdapat pada lotion kombinasi minyak atsiri daun zodia dan minyak atsiri batang serai. Semakin banyak kandungan minyak atsiri yang ditambahkan pada komposisi produk (lotion atau sabun) maka semakin semakin tinggi daya proteksinya (Simaremare dkk., 2018) karena faktor penguapan minyak atsiri yang semakin lama.

\section{Kesimpulan}

Hasil dari penelitian ini adalah

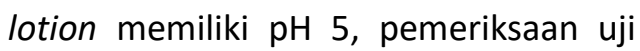
sentrifugasi menunjukkan lotion tidak terpisah/stabil. Efektivitas penghalau nyamuk sediaan lotion paling tinggi pada jam ke-0 dengan daya halau 100\%. Kombinasi terbaik sediaan lotion kombinasi minyak atsiri daun zodia (Evodia suaveolens Scheff) dan minyak atsiri batang serai (Cymbopogon citratus) sebagai repellent nyamuk Aedes aegypti yaitu 7:3.

\section{Daftar Pustaka}

Agustina, L. 2010. Formulasi Iosion pencerah kulit dari sarang burung walet putih (Aerodramus fuciphagus) dengan keragian sebagai bahan pengental. Skripsi. Fakultas Kedokteran, Universitas Tanjungpura.

Astuti, S. 2006. Isolasi dan identifikasi komponen minyak atsiri umbi teki (Cyperus Rotundus L.). Skripsi. Fakultas MIPA, Universitas Sebelas Maret Surakarta.

Bernard. 2000. Repellents and Toxicants for Personal Protection. Florida: Global Collaboration for Development of Pesticides for Public Health (GCDPP) WHO.

Guenter, E. 1948. The Essential Oil. Vol. 4 (Minyak Atsiri). Ketaren (terjemahan). Jakarta: Universitas Indonesia Press.

Juniarti, Y.E.S. 2011. Distilasi minyak atsiri daun surian sebagai pencegah gigitan nyamuk Aedes aegypti L. Makara Sains, 15(1):38-42.

Kardinan, A. dan Jasni. 2001. Effect of some botanical insecticides against dry wood termiter Cryptotermes cynocephalus. Prosiding International Seminar on Natural Products Chemistry and Utilization of Natural Resources, Unesco-University of Indonesia.

Kardinan, A. 2003. Tanaman Pengendali Hama Lalat Buah. Jakarta: Argomedia Pustaka.

Kardinan, A. 2004. Pengaruh minyak biji nimba (Azadirachta indica) sebagai daya penolak makan dan insektisida pada serangga Dolleshalia pollibete. Jurnal 
IImiah Pertanian Gakuryoku, 10(2):153-156.

Kardinan, A. 2005. Tanaman Pengusir dan Pembasmi Nyamuk. Jakarta: Argomedia Pustaka.

Kardinan, A. 2007. Tanaman Pengusir dan Pembasmi Nyamuk. Jakarta: Argomedia Pustaka.

Kardinan, A. dan Dhalimi, A. 2010. Potensi adas (Foeniculum vulgare) sebagai bahan aktif lotion anti nyamuk demam berdarah (Aedes aegypti). Bul. Littro, 21(1):61-68.

Lestari, F.D. dan Simaremare, E.S. 2017. Uji potensi minyak atsiri daun zodia (Evodia suaveolens Scheff) sebagai insektisida nyamuk Aedes aegypti dengan metode elektrik. Pharmacy, 14(1):1-10.

Novizan. 2002. Membuat dan Memanfaatkan Pestisida Ramah Lingkungan. Jakarta: PT. Agro Media Pustaka.

Purnamasari, B., Simaremare, E.S., dan Agustini, V. 2015. Uji efektivitas lotion repellent minyak atsiri daun zodia (Evodia suaveolens Scheff) terhadap nyamuk Aedes aegypti. Prosiding Seminar PBI
ke-XXIII, Jayapura 8-9 September 2015.

Simaremare, E.S. dan Gunawan, E. 2015. Formulasi dan evaluasi sediaan lotion ekstrak etanol daun zodia (Evodia Suaveolens Scheff) sebagai repelen terhadap nyamuk malaria Anopheles sp. Prosiding Seminar Hasil Penelitian Pengembangan Ipteks dan SainsLPPM Uncen.

Simaremare, E.S.D. Sinaga, D.I., Agustini, V. 2017. Sabun padat zodia sebagai repellent terhadap nyamuk Aedes aegypti. Pharmaceutical Journal of Indonesia, 3(1):63-71.

Simaremare, E.S., Manurung, L., Gunawan, E., dan Maryuni, A.E. 2018. Zodia (Evodia suaveolens Scheff) in liquid soap as repellent against Aedes aegypti L. Advanced Sciences Letters, 24:9194.

Yuniarsih, E. 2010. Uji efektivitas losion repellent minyak nimba (Azadirachta indica A. Juss) terhadap nyamuk Aedes Aegypti. Skripsi. Universitas Islam Negeri (UIN) Syarif Hidayatullah, Jakarta. 